\title{
Intrathecal baclofen - a multicentre clinical comparison of the Medtronics Programmable, Cordis Secor and Constant Infusion Infusaid drug delivery systems
}

\author{
B Gardner ${ }^{1}$, A Jamous ${ }^{1}$, P Teddy ${ }^{1}$, E Bergstrom $^{1}$, D Wang ${ }^{1}$, G Ravichandran ${ }^{2}$, R Sutton ${ }^{3}$ and S Urquart ${ }^{3}$ \\ ${ }^{1}$ National Spinal Injuries Centre, Stoke Mandeville Hospital, Aylesbury, HP21 8AL; ${ }^{2}$ Regional Spinal Injuries \\ Centre, Northern General Hospital, Sheffield and ${ }^{3}$ Northern Regional Spinal Injuries Centre, Hexham General \\ Hospital, Hexham UK
}

\begin{abstract}
A retrospective review was carried out of 34 consecutive traumatic spinal cord damaged patients who have had the Medtronics Programmable, Cordis Secor or Constant Infusion Infusaid intrathecal baclofen drug delivery systems inserted between July 1987 and 1992. The results indicate that whilst this treatment has many benefits there is a significant risk of complications, some potentially fatal. It should only be provided by a skilled and experienced team. The Medtronics Programmable pump is an excellent pump. It is of particular benefit where the therapeutic window is small or fine-tuning required. The Constant Infusion Infusaid is adequate if less precise control and continuous infusion is sufficient. It is of particular benefit in financially disadvantaged countries. The Cordis Secor device is helpful when unpredictable intermittent relief of spasticity is required but is otherwise limited by its complication rate.
\end{abstract}

Keywords: spinal cord injury; spinal paralysis; intrathecal; baclofen; pumps; comparison; spasticity; spasms

\section{Introduction}

Baclofen relieves spasticity through its action as an analogue of the central inhibitory neurotransmitter gamma-amino-butyric acid. Its benefit when taken orally is limited by its poor penetration of the bloodbrain barrier and the incidence of unwanted cerebral effects.

In 1983 Penn demonstrated that tiny quantities of baclofen injected into the lumbar cerebrospinal fluid relieves severe spasticity and spasms without causing unwanted cerebral effects. It is now established as an important treatment for intractable generalised spasticity. ${ }^{1-13}$

This retrospective clinical study compares the use of the Medtronics Programmable, Cordis Secor and Constant Infusion Infusaid drug delivery systems in traumatic spinal cord injured patients with severe intractable spasticity and spasms.

\section{Patients and methods}

A retrospective review was carried out of the medical records of all traumatic spinal cord damaged patients who have had the Medtronics Programmable, Cordis Secor or Constant Infusion Infusaid intrathecal baclofen drug delivery systems implanted in the National Spinal Injuries Centre, the Paddocks Hospital Spinal Unit, Lodge Moor Hospital Spinal Unit, the Northern Regional Spinal Injuries Unit, Hexham and The
Radcliffe Infirmary, Oxford between July 1987 and 1992. The notes of one patient, whose first implant was a Medtronics Programmable pump, could not be found. The manufacturer's guidelines on pump insertion, refills and maintenance were followed. Patients were contacted to indicate their satisfaction or otherwise with the treatment.

\section{Results}

Thirty four patients with intractable spasticity following traumatic spinal cord injury had a total of 43 intrathecal baclofen drug delivery systems implanted. Twenty five were male and nine female. The cause of injury was car in fourteen, motorcycle in seven, fall in eight, diving in two, stabbing in two and rugby in one. Age at the time of the first implantation ranged from 18 to 62 with a mean of 34. Sixteen of the patients had had a cervical injury, of whom half had complete and half incomplete neural lesions; and 18 thoracic, 12 of whom had complete and six incomplete neural lesions.

Intrathecal test bolus doses of baclofen were given. The amount required to nearly abolish spasticity and spasms varied from 25 to $100 \mu \mathrm{g}$. The effect lasted for between 6 and $24 \mathrm{~h}$.

The initial pump insertion of 23 patients was in Stoke Mandeville Hospital, one in the Paddocks Hospital, two in the Radcliffe Infirmary, four in Lodge Moor Hospital and four in Hexham General Hospital. Fifteen 
of the first implanted pumps were Cordis Secor, 17 Medtronics Computerised and two Constant Infusion Infusaid.

Eighty four operations were carried out, excluding insertions of injection ports. Twenty three of the 34 patients required reoperation. The complications are shown in Table 1. Total implant times in months include both first implants and later implants where a Medtronics or Infusaid pump replaced the Cordis Secor.

Pump characteristics are compared in Table 2.

The precise daily dose used by patients with the Cordis pumps was not easily assessed but in most cases between 200 and $400 \mu \mathrm{g}$ daily was required. The dose required by those with programmable pumps was between 50 and $1,440 \mu \mathrm{g} \mathrm{day}^{-1}$. Where rapid increases in dose requirements occurred this usually indicated a problem in the drug delivery system requiring surgery.

Patient assessments received indicated satisfaction with the results of the treatment in 24 patients, despite delivery system management problems, and dissatisfaction in seven. The overwhelming majority of those satisfied with the treatment expressed this in glowing terms, many patients indicating that their lives had been transformed. The level of satisfaction of three of the patients is unknown.

Patient dissatisfaction was expressed in five patients where the first implant was a Cordis Secor and in two where it was the Medtronics Computerised. Both

Table 1 Complications of treatment

\begin{tabular}{|c|c|c|c|}
\hline Feature & $\begin{array}{l}\text { Cordis } \\
\text { Secor }\end{array}$ & Medtronics & Infusaid \\
\hline $\begin{array}{l}\text { Total number of first } \\
\text { implants }\end{array}$ & 15 & 17 & 2 \\
\hline Pump removals & 11 & 2 & 0 \\
\hline Reimplants required & 7 & 2 & 0 \\
\hline $\begin{array}{l}\text { Number of patients } \\
\text { requiring reoperation }\end{array}$ & 12 & 10 & 1 \\
\hline $\begin{array}{l}\text { Total implant times in } \\
\text { months }\end{array}$ & 262 & 567 & 73 \\
\hline Total complications & 25 & 23 & 1 \\
\hline $\begin{array}{l}\text { Tube dislodgement from } \\
\text { subarachnoid space }\end{array}$ & 5 & 4 & 1 \\
\hline Tube disconnection & 1 & 5 & 0 \\
\hline $\begin{array}{l}\text { Tube kinking or } \\
\text { blockage }\end{array}$ & 0 & 6 & 0 \\
\hline Tube breakage & 0 & 1 & 0 \\
\hline Pump malfunction & 0 & 2 & 0 \\
\hline Significant CSF leak & 1 & 1 & 0 \\
\hline Wound haematoma & 2 & 1 & 0 \\
\hline $\begin{array}{l}\text { Skin necrosis or } \\
\text { breakdown }\end{array}$ & 3 & 0 & 0 \\
\hline Infection & 7 & 0 & 0 \\
\hline Mild drug overdose & 3 & 0 & 0 \\
\hline Serious drug overdose & 0 & 2 & 0 \\
\hline Inability to use the pump & 2 & 0 & 0 \\
\hline $\begin{array}{l}\text { Reluctance to use the } \\
\text { pump for psychological } \\
\text { reasons }\end{array}$ & 1 & 1 & 0 \\
\hline
\end{tabular}

patients whose first implant was the Constant Infusion Infusaid were satisfied.

Spasticity was greatly reduced in all cases provided that the pump was functional. One patient required rhizotomy in addition to the Infusaid system. Significant symptomatic bladder ${ }^{14-16}$ or bowel functional change did not arise except in two patients who became more constipated.

Pain associated with spasticity was reduced in three patients. Neurogenic pain was unaltered. No patient had increased pain.

Inability to use the Cordis Secor pump effectively was in one patient caused by fibrosis and in the second by alteration of the position of the pump.

Eleven of the 15 Cordis Secor first implants have been removed, seven as a result of infection, two following skin breakdown, one after mild overdose and one because the patient could not locate the drug delivery buttons as a result of fibrosis. The two serious drug overdoses in the Medtronics group did not require pump removal as the cause was identified and remedied to make a repetition unlikely.

Of the nine pump replacements as a result of complications, three were Cordis Secor replacing Cordis Secor, three Medtronics Computerised replacing Cordis Secor and one a Constant Infusion Infusaid replacing a Cordis Secor. Two Medtronics computerised pumps required replacement. No Constant Infusion Infusaid pump has required replacement.

The seven infections with the Cordis Secor pump include one pump infection, five wound infections and one instance of meningitis.

Mild drug overdoses caused drowsiness and excessive flaccidity. The serious overdoses endangered life and required ITU admission. No overdose problem has occurred to date with the Infusaid pumps. Physostigmine given in cases of serious overdose ${ }^{1+}$ was found to be of short-lived benefit. Intubation and ventilation were the mainstays of treatment.

One additional patient, lost to follow-up and therefore not included in this series, had a Cordis Secor pump inserted at the Radcliffe Infirmary. It was removed after approximately 6 weeks because of deliberate misuse by the patient.

Pump accuracy was measured in some patients. The accuracy of the Medtronics pump, as indicated by the actual minus the programmer predicted residual, was usually less than $1.0 \mathrm{cc}$, and often less than $0.5 \mathrm{cc}$. In the case of the Cordis Secor, the actual minus predicted residual was usually less than $2 \mathrm{cc}$. This was of no importance in clinical terms except in the cases of the mild Cordis Secor drug overdoses where there was inability of the patient to detect the pump buttons with certainty, or pump inaccuracy or both.

\section{Discussion}

Troublesome spasticity is a common consequence of central nervous system injury, in particular spinal cord damage. Correction of precipitating factors, such as 
Table 2 Comparison of the pumps

\begin{tabular}{llll}
\hline & Cordis & Medtronics & Infusaid \\
\hline Patient satisfaction & + & ++ & ++ \\
Drug delivery & Intermittent $0.1 \mathrm{ml}$ bolus & Variable computerised & Continuous $1-5 \mathrm{ml}$ day -1 \\
Reservoir volume (cc) & 12 & 18 & 50 \\
Pump size & + & ++ & ++ \\
Implantation site of pump & Chest & Abdomen & Abdomen \\
Control & Manual button & Computer programmed & Variable pump drug \\
& & & concentration \\
Ease of catheter insertion & ++ & + & ++ \\
Ease of pump insertion & + & ++ & ++ \\
Accuracy & + & +++ & ++ \\
Bacterial filter & - & + & + \\
Suicide risk & + & - & + \\
Overall complications & ++++ & ++ & Lifetime \\
Pump life (years) & 4 & $4-6$ & +++ \\
Implant cost & + & +++ & + \\
Total cost & +++ & +++ & + \\
Fine-tuning control & + & +++ & +++ \\
Ease of patient use & + & +++ & + \\
Ease of refill & + & + & +++ \\
Convenience of refill & +++ & + & + \\
\hline
\end{tabular}

vesical or perianal pathology, will often relieve the symptoms. Physiotherapy is often helpful.

Focal spasticity may be resolved by local approaches, such as microrootlet rhizotomy and somatic motor-end point injection. Widespread spasticity often requires medications such as dantrolene sodium, diazepam and baclofen. These are not always effective and frequently have unwanted effects.

In a small number of patients intractable spasticity persists. It is for these that intrathecal delivery of baclofen is sometimes indicated. All three pumps evaluated here are effective in this regard.

The accurate control afforded by the Medtronics programmable pump is useful when the therapeutic window is small or fine tuning of the level of spasticity is required to achieve optimum function. In most cases it meets very effectively the needs of the patient. It is usually the drug delivery system of choice.

The Cordis Secor pump may be helpful if there is an intermittent irregular requirement, such as the relief of anal spasm prior to bowel evacuation. It is contraindicated where a suicide risk is present. Patients unable to master the buttons should not have this system because of the risk of overdosage. Its high incidence of complications is a serious drawback.

The Constant Infusion Infusaid pump is preferred where continuous intrathecal baclofen infusion meets the clinical need and the therapeutic window does not require precise dose control. Patients from financially disadvantaged countries are particularly likely to benefit from this pump. Even if there is a computer programmer in their country it may well be a long or difficult journey away. In addition the funding required for first implantation may not be available for subsequent replacements, which are inevitable with the Medtronics pump.

The results of this study indicate that there is a significant incidence of complications associated with intrathecal baclofen delivery. Some of these, in particular infection and intrathecal drug overdose, are potentially fatal. In spite of this, $80 \%$ of the patients of this study were satisfied with the majority of these indicating that the quality of their lives had been dramatically improved by the therapy.

The complications of skin necrosis and inability to use the pump were confined to the Cordis Secor device. This pump requires placement close to the skin surface, increasing the risk of skin breakdown. In addition, difficulties with palpating the buttons and uncertainty regarding whether or not a dose has been delivered increases the risk of inadvertent overdose. Deliberate overdose is also possible. The absence of a bacterial filter and the greater risk of skin necrosis increases the likelihood of infection.

In these times of severe resource restriction there is a strong incentive to insert a pump like the Cordis Secor that is much less expensive than the Medtronics Computerised and does not require the initial additional outlay of the external computerised pump programmer. However, any initial capital saving may be offset by expenses associated with subsequent complications or pump reimplantations. Recent design modifications in the Cordis Secor pump are unlikely to have completely overcome these problems.

Successful application of this valuable but hazardous treatment requires a careful evaluation of the patient, not only of his response to the intrathecal test dose but also of his ability to cope with the pump and the regular refills required. Safer alternative approaches for relieving spasticity should be fully evaluated in the first instance. The patient must be physically and psychologically able to cope with the system, especially with the Cordis Secor where manual operation is required.

The implantation must be carried out by an experi- 
enced team. Although the procedures involved are straightforward, careful attention to detail is essential if the incidence of reoperations is to be kept to a minimum.

Postoperative pump management must be carefully coordinated so that the patient is well educated, pump refills with dose adjustments are carried out easily and safely, and complications are diagnosed promptly and treated appropriately.

\section{Conclusions}

Implanted baclofen drug delivery systems are an important though still hazardous treatment for the spinal cord damaged patient with intractable spasticity. Successful application requires a closely coordinated and integrated team for the assessment, implantation and subsequent follow-up of the patient.

The accurate control afforded by the Medtronics programmable pump is useful when the therapeutic window is small or fine tuning of the level of spasticity is required to achieve optimum function. Although it is expensive and requires replacement every 4-6 years its reliability and low incidence of complications makes it an economic choice. Overall it is a very satisfactory system for the safe delivery of intrathecal drugs.

There is little place for the Cordis Secor pump except when there is an intermittent irregular requirement, such as the relief of anal spasm prior to bowel evacuation. It is contraindicated where a suicide risk is present or patient compliance is in doubt. In spite of the lower initial cost of this pump the high incidence of problems makes it overall a more expensive option.

The experience with the Infusaid pump is too small to draw firm conclusions but the initial results suggest that it is probably the optimal choice of pump for patients who require only continuous delivery of baclofen and whose therapeutic window is large. It has a particular value for patients in financially disadvantaged countries who are unlikely to be able to afford to return for pump replacement every 4-6 years and probably do not have access to a Medtronics pump computer program.

\section{References}

1 Penn RD, Kroin JS. Continuous intrathecal baclofen alleviates spinal cord spasticity. Lancet $1984 ; 1$ : 1078.

2 Broseta $\mathrm{J}$ et al. The use of intrathecal baclofen administered by programmable infusion pumps in persistent spasticity. Acta Chir Suppl Wien 1989; 46: 39-45.

3 Broseta $\mathrm{J}$ et al. Chronic intrathecal baclofen administration in severe spasticity. Stereotactic Funct Neurosurg 1990; 33: $147-153$.

4 Hankey GJ, Stewart-Wunne EG, Perlman D. Intrathecal baclofen for severe spasticity. Med J Aust 1986; 145: 465-466.

5 Latash ML, Penn RD, Corcos DM, Gottlieb GL. Effects of intrathecal baclofen on voluntary motor control in spastic paresis. J Neurosurg 1990; 72: 388-392.

6 Lazorthes Y. Chronic intrathecal administration of baclofen in treatment of severe spasticity. In: Muller H, Zierski J, Penn RD (eds) Local-spinal Therapy of Spasticity. Springer-Verlag: Berlin, Heidelberg, New York, London, Paris, Tokyo, 1988, pp 215-222.

7 Lazorthes $\mathrm{Y}$, et al. Chronic intrathecal baclofen administration for control of severe spasticity. J Neurosurg 1990; 72: 393-402.

8 Loubser PG et al. Continuous infusion of intrathecal baclofen: long-term effects on spasticity in spinal cord injury. Paraplegia 1991; 29: 48-64.

9 Muller $\mathrm{H}$ et al. Intrathecal baclofen in spasticity. In: Muller $\mathrm{H}$, Zierski J, Penn RD (eds). Local-spinal Therapy of Spasticity. Springer-Verlag: Berlin, Heidelberg, New York, London, Paris, Tokyo, 1988, pp 155-214.

10 Ochs G et al. Intrathecal baclofen for long-term treatment of spasticity: a multi-centre study. J Neurol Neurosurg Psychiatry 1989; 52: 933-939.

11 Penn RD, Kroin JS. Continuous intrathecal baclofen for severe spasticity. Lancet 1985; 11: 125-127.

12 Siegfried J, Rea GL. Intrathecal application of baclofen in the treatment of spasticity. Acta Neurochir Suppl Wien 1987; 39: 121-123.

13 Zierski J, Muller H, Dralle D, Wurdinger T. Implanted pump systems for treatment of spasticity. Acta Neurochir Suppl Wien 1988; 43: 94-99.

14 Talalla A, Grundy D, MacDonell R. The effect of intrathecal baclofen on the lower urinary tract in paraplegia. Paraplegia 1990; 28 : 420-427.

15 Frost F, Nanninga J, Penn R, Savoy, Wu Y. Intrathecal baclofen infusion. Effect on bladder management programmes in patients with myelopathy. Am J Phys Med Rehabil 1989; 68: $112-115$.

16 Nanninga JB, Frost F, Penn R. Effect of intrathecal baclofen on bladder and sphincter function. J Urol 1989; 142: 101-105.

17 Muller-Schwefe G, Penn RD. Physostigmine in the treatment of intrathecal baclofen overdose. Report of three cases. J Neurosurg 1989; 71: 273-275. 